\title{
Low strength ultrasonication positively affects the methanogenic granules toward higher AD performance. Part l: Physico-chemical characteristics
}

Cho, S. K.; Hwang, Yuhoon; Kim, D. H.; Jeong, I. S.; Shin, H. S.; Oh, S. E.

Published in:

Bioresource Technology

Link to article, DOI:

10.1016/j.biortech.2013.02.111

Publication date:

2013

Link back to DTU Orbit

Citation (APA):

Cho, S. K., Hwang, Y., Kim, D. H., Jeong, I. S., Shin, H. S., \& Oh, S. E. (2013). Low strength ultrasonication positively affects the methanogenic granules toward higher AD performance. Part I: Physico-chemical characteristics. Bioresource Technology, 136, 66-72. https://doi.org/10.1016/j.biortech.2013.02.111

\section{General rights}

Copyright and moral rights for the publications made accessible in the public portal are retained by the authors and/or other copyright owners and it is a condition of accessing publications that users recognise and abide by the legal requirements associated with these rights.

- Users may download and print one copy of any publication from the public portal for the purpose of private study or research.

- You may not further distribute the material or use it for any profit-making activity or commercial gain

- You may freely distribute the URL identifying the publication in the public portal 


\section{Accepted Manuscript}

Low strength ultrasonication positively affects the methanogenic granules toward higher AD performance. Part I: physico-chemical characteristics

Si-Kyung Cho, Yu-Hoon Hwang, Dong-Hoon Kim, In-Seok Jeong, Hang-Sik Shin, Sae-Eun Oh

PII: S0960-8524(13)00346-5

DOI: http://dx.doi.org/10.1016/j.biortech.2013.02.111

Reference: BITE 11450

To appear in:

Bioresource Technology

Received Date:

30 November 2012

Revised Date:

22 February 2013

Accepted Date:

27 February 2013

Please cite this article as: Cho, S-K., Hwang, Y-H., Kim, D-H., Jeong, I-S., Shin, H-S., Oh, S-E., Low strength ultrasonication positively affects the methanogenic granules toward higher AD performance. Part I: physicochemical characteristics, Bioresource Technology (2013), doi: http://dx.doi.org/10.1016/j.biortech.2013.02.111

This is a PDF file of an unedited manuscript that has been accepted for publication. As a service to our customers we are providing this early version of the manuscript. The manuscript will undergo copyediting, typesetting, and review of the resulting proof before it is published in its final form. Please note that during the production process errors may be discovered which could affect the content, and all legal disclaimers that apply to the journal pertain. 


\title{
Low strength ultrasonication positively affects the methanogenic granules toward higher AD performance. Part I: physico-chemical characteristics
}

Si-Kyung Cho ${ }^{\mathrm{a}}$, Yu-Hoon Hwang ${ }^{\mathrm{a}, \mathrm{d}}$, Dong-Hoon Kim ${ }^{\mathrm{b}}$, In-Seok Jeong ${ }^{\mathrm{c}}$, Hang-Sik Shin ${ }^{\mathrm{a}}$, SaeEun $\mathrm{Oh}^{\mathrm{c}, *}$

a Department of Civil and Environmental Engineering, KAIST, 291 Daehak-ro, Yuseong-gu, Daejeon, Republic of Korea

${ }^{\mathrm{b}}$ Clean Fuel Department, Korea Institute of Energy and Research, 102 Gajeong-ro, Yuseonggu, Daejeon, Republic of Korea

${ }^{c}$ Department of Environmental Engineering, Hanbat National University, San 16-1, Duckmyoung-dong, Yuseong-gu, Daejeon, Republic of Korea

${ }^{\mathrm{d}}$ Department of Environmental Engineering, Technical University of Denmark, Miljøvej, Bygning 113, DK-2800 Kgs. Lyngby, Denmark

* Correspondence: +82 428211263 (phone), +82 428211476 (fax), saeun@hanbat.ac.kr

\begin{abstract}
To elucidate the correlation between enhanced biogas production and changed physico-chemical properties of methanogenic granules after low strength ultrasonication, in this study, the effects of low strength ultrasonication on the settling velocity, permeability, porosity, and fluid collection efficiency of the methanogenic granules were investigated. In addition, their morphological changes were visualized using a scanning electron microscopic technique. The experimental results indicate that low strength ultrasonication increased both the permeability (37\%) and specific surface area (230\%) of the granules through the generation of greater craters and cracks on the granular surface compared to the control
\end{abstract}


granules. The penetration of nutrients and substrate into the granules was thereby enhanced, and more favorable conditions for achieving higher anaerobic performance were provided to the ultrasonicated granules. The microbial community shift caused by the changed physicochemical properties of the methanogenic granules will be further analyzed in part II of this study.

Keywords: Low strength ultrasonication, UASBr, permeability, specific surface area, scanning electron microscope

\section{INTRODUCTION}

Ultrasound, a sound wave at a frequency above the human hearing range of $20 \mathrm{kHz}$, has been widely applied to welding, degassing of solutions, defecting detection, etc (Kwiatkowska et al., 2011). When ultrasound is applied to a liquid phase, cavitation bubbles are generated in the rarefaction region. As a result of cavitation rupture, the hydro-mechanical shear stress localizes and temperature increases up to 5,000 K, and highly reactive $\mathrm{OH}^{-}$ radicals are generated (Riesz and Kondo, 1992). In addition, an increase in mixing and mass transfer was also observed in an aqueous solution or suspension (Kwiatkowska et al., 2011). To exploit these beneficial effects, ultrasound also has been applied to environmental fields for intracellular material recovery, enzyme extraction, etc (Harrison, 1991). Many researchers in the field of anaerobic digestion (AD) have also applied ultrasonication to improve the efficiency of the $\mathrm{AD}$ processes, resulting in increased methane production and considerable reduction of digestion time (Gogate and Kabadi, 2009; Pilli et al., 2011).

The types of ultrasonication on AD can be classified as high and low strength based on where ultrasonication is irradiated (Cho et al., 2012). High strength ultrasonication (HSultrasonication) refers to when ultrasonication is irradiated to a feedstock as a pretreatment, whereas low strength ultrasonication (LS-ultrasonication) is irradiated to the reactor itself to 
target microorganisms involved in the AD process. Therefore, different mechanisms need to be applied in order to explain the performance enhancement between LS-ultrasonication and HS-ultrasonication. While the enhancement of $\mathrm{AD}$ performance by LS-ultrasonication is attributed to increased microbial activity through the stimulation of biological enzymes, the latter is explained by an increase of substrate availability in solubilizing inert and slowly biodegradable sections.

The majority of research has predominantly focused on HS-ultrasonication. Using this technique, $64 \%$ methane $\left(\mathrm{CH}_{4}\right)$ yield enhancement through 30 min of ultrasonication time (UT) $(20 \mathrm{~W}, 9 \mathrm{kHz})$ and 51\% $\mathrm{CH}_{4}$ yield enhancement through ultrasonication by 9,350 $\mathrm{kJ} / \mathrm{kg}$ TS have been reported (Wang et al., 1999; Bougrier et al., 2006). In addition, a significant increase in $\mathrm{CH}_{4}$ yield, from 82 to $127 \mathrm{mlCH}_{4} / \mathrm{g} \mathrm{COD}$ added, by combining alkaline pretreatment ( $\mathrm{pH}$ 9) with 7,000 kJ/kg TS ultrasonication was also reported (Kim et al., 2010). However, relatively little attention has been dedicated to investigate the application of LSultrasonication in the AD system. Elbeshbishy et al. (2011) applied ultrasonication (0.25 $\mathrm{W} / \mathrm{mL}, 1 \mathrm{sec}$ per $1 \mathrm{~min}$ ) to hydrogen production using a continuous stirred tank reactor. Enhanced hydrogen production rate $(2.8 \mathrm{~L} / \mathrm{L} / \mathrm{d} \rightarrow 5.6 \mathrm{~L} / \mathrm{L} / \mathrm{d})$, hydrogen yield $(1.0 \mathrm{~mol} \mathrm{H} / \mathrm{mol}$ glucose $\rightarrow 1.9 \mathrm{~mol} \mathrm{H}_{2} / \mathrm{mol}$ glucose $)$, and glucose conversion efficiency $(76 \% \rightarrow 84 \%)$ were reported at a $32.1 \mathrm{~g} \mathrm{COD} / \mathrm{L} / \mathrm{d}$ of organic loading rate. In our previous research, the first work to apply ultrasonication to an upflow anaerobic sludge blanket reactor (UASBr) for methane production, $43 \%$ higher methane production was achieved under continuous ultrasonication (0.05 W/mL, $1 \mathrm{sec}$ per $1 \mathrm{~min})$ (Cho et al., 2012).

Most explanations of enhanced biogas production after LS-ultrasonication have focused on biological point of views. In Elbeshbishy et al. (2011)'s research, increased microbial growth rate and the existence of two different hydrogen producers (Clostridium $s p$. and C. freundii), detected only in the ultrasonicator attached reactor, were attributed to 
enhanced hydrogen production. In addition, in our previous research, increased dehydrogenase activity and adenosine triphosphate content, by $257 \%$, and $374 \%$, respectively, compared to the control was observed after ultrasonication (Cho et al., 2012). However, there has been no attempt to explain the enhanced biogas production after LS-ultrasonication on the basis of the changes of physico-chemical characteristics of microbial granules (aggregates), despite that they could directly influence substrate and nutrient transportation in anaerobic microorganisms (Mu et al., 2006).

In this study, first, the effects of LS-ultrasonication were investigated during continuous operation of a UASBr. The effects of LS-ultrasonication on the physico-chemical properties of methanogenic granules (settling velocity, permeability, porosity, and fluid collection efficiency) were then investigated to elucidate the correlation between enhanced biogas production and changed physico-chemical characteristics of methanogenic granules after LS-ultrasonication. In addition, scanning electron microscopy (SEM) and specific surface area of methanogenic granules were analyzed to visualize the effects of LSultrasonication.

\section{MATERIALS AND METHODS}

\subsection{System setup and operating conditions at $U A S B r$}

The methanogenic granules used in this study were obtained from a full scale anaerobic plant treating brewery wastewater located in Cheongwon, Korea. In addition, the full scale anaerobic plant was operating under same conditions at the sampling period of Phase I and II. The pH and concentrations of volatile suspended solids (VSS) were 7.6 and $105.4 \mathrm{~g} / \mathrm{L}$, respectively. Five L of UASBr (lower part: $690 \mathrm{~mm}$ height x $85 \mathrm{~mm}$ inside diameter (i.d.); upper part: $165 \mathrm{~mm}$ height x $130 \mathrm{~mm}$ i.d.) installed with four vibrators $(50 \mathrm{~W}$, $20 \mathrm{kHz}$ ) was prepared for the tests (Cho et al., 2012). 
In the continuous operation of UASBr, $5 \mathrm{~g}$ chemical oxygen demand (COD)/L of acidified mixture (food waste and livestock waste; $\mathrm{V}: \mathrm{V}=6: 4$ ) was fed at an organic loading rate (OLR) of $2.5 \mathrm{~g} \mathrm{COD/L/day.} \mathrm{The} \mathrm{produced} \mathrm{gas} \mathrm{was} \mathrm{collected} \mathrm{by} \mathrm{a} \mathrm{gas} \mathrm{collector} \mathrm{and}$ sampled using a $1 \mathrm{ml}$ syringe to analyze $\mathrm{CH}_{4}$ content.

\subsection{Determination of physico-chemical characteristics of methanogenic granule}

\subsubsection{Settling experiments}

The experimental apparatus for the settling of granules consisted of a transparent acrylic column and a collection unit. The column was $500 \mathrm{~mm}$ in height to ensure that the terminal settling velocity could be reached, and $50 \mathrm{~mm}$ in internal diameter to minimize the wall effect on granule settling. Settling velocities were measured at a depth of $35-45 \mathrm{~cm}$ below the release point. The top of the column was sealed with an acrylic plate that incorporates a $10 \mathrm{~mm}$ hole for introduction of granules. The collection unit consists of a bottom well for the filter paper and a filtration unit composed of a Buchner funnel and vacuum pump.

Before the settling experiment, the glass fiber filter paper $(1.2 \mathrm{um}, 47 \mathrm{~mm}$, Whatman, USA) was placed on the bottom well of the collection unit. After the settling apparatus was filled with distilled water, each granule was transferred using a pipette with a $1 \mathrm{~mL}$ pipette tip cut midway to minimize breakup of the granules. The granules were placed into the top of the settling column, and the settling velocity was measured. After the settling experiment, the water was discharged through the valve ( $3 \mathrm{~cm}$ from filter paper). The remaining water in the bottom well was drawn out by vacuum filtration through filter paper. The granules on the filter paper were transferred for subsequent analysis.

The filter paper was placed in a Petri dish $(9.5 \mathrm{~cm})$ to measure its size. Each granule was photographed using a Digital Single Lens Reflex (DSLR) camera (Canon EOS 450D, 
Canon, Japan), and the photos were then processed with a computer-based image analysis system (Sigma Pro 5, Jandel Scientific, Erkrath, Germany). The granule size (projection diameter) was determined by calculating the diameter of the circle, which has the same projection area as the granule.

After the image analysis, the dry mass of the granule was measured. The granule was dried at $105^{\circ} \mathrm{C}$ for $1.5 \mathrm{~h}$ on pre-weighted glass fiber filter paper, and its dry mass, $\mathrm{W}_{\mathrm{d}}$, was measured using an electronic microbalance (PAG214C, OHAUS, USA). The combined weight of the dry filter and granules minus the weight of the filter gave the mass of the granules.

\subsubsection{Calculated granule properties}

\subsubsection{Stokes' law for porous but impermeable microbial granule}

The terminal settling velocity of a single impermeable sphere particle under gravity can be derived from a force balance among the forces of buoyancy, drag, and gravity, which produces the generalized Stokes' law (Li and Yuan, 2002):

$$
U_{s}=\left[\frac{4 g\left(\rho_{a}-\rho_{l}\right) d}{3 \rho_{l} C_{d}}\right]^{1 / 2}
$$

where $\mathrm{g}$ is the gravitational constant $\left(\mathrm{cm} / \mathrm{s}^{2}\right), \rho_{\mathrm{a}}$ is the density of the sphere $\left(\mathrm{g} / \mathrm{cm}^{3}\right), \rho_{1}$ is the density of the liquid $\left(\mathrm{g} / \mathrm{cm}^{3}\right)$, and $C_{d}$ is the empirical drag coefficient. $C_{d}$ is adjusted for higher Reynolds numbers $(\operatorname{Re}>1)$ and can be obtained from the following equation (White, 2005).

$$
C_{d}=\frac{24}{R e}+\frac{6}{1+\sqrt{R e}}+0.4
$$

with 


$$
\operatorname{Re}=\rho_{l} U d / \mu
$$

where $U$ is the actual settling velocity $(\mathrm{cm} / \mathrm{s})$ and $\mu$ is the fluid viscosity $(\mathrm{g} / \mathrm{cm} / \mathrm{s})$.

For a porous bacterial granule with water in the interior pores, the overall density is a function of the porosity $\varepsilon$, as predicted according $\rho_{a}-\rho_{l}=(1-\varepsilon)\left(\rho_{c}-\rho_{l}\right)$, where $\rho_{c}$ is the density of the bacterial cells (Johnson et al., 1996). Here it is assumed that a factor $\mathrm{f}$ is the dimensionless ratio between the wet mass and dry mass of the cells, and $\mathrm{W}_{\mathrm{d}}$ is the dry mass of the bacterial aggregate. Thus, the aggregate porosity becomes

$$
\epsilon=1-\frac{6 f W_{d}}{\pi \rho_{c} d^{3}}
$$

Therefore, the settling velocity of a microbial aggregate predicted from Stokes' law may be derived as given below ( $\mathrm{Li}$ and Yuan, 2002).

$$
U_{s}=\left[\frac{8 g \mathrm{f}}{\pi}\left(\frac{1}{\rho_{l}}-\frac{1}{\rho_{c}}\right) \frac{W_{d}}{C_{d} d^{2}}\right]^{1 / 2}
$$

The two parameters for the general characteristics of cells, $\rho_{c}$ and $f$, were determined separately. The granule density was determined according to the sucrose solution method (Zheng et al., 2005). In this way, the wet specific gravity of granules was measured. In this study, granule density was obtained as 1.075 and $1.055 \mathrm{~g} / \mathrm{cm}^{3}$ for the control granule and ultrasonicated granule, respectively. The ratio factor between the wet mass and dry mass of bacteria was estimated using the following equation (Metcalf \& Eddy, 2002).

$$
\mathrm{f}=\frac{W_{w}^{c}-W_{w}^{f}}{W_{d}^{c}-W_{d}^{f}}
$$

where $W_{w}^{e}$ is the weight of the filter after filtration (filter + granule, moistened), $W_{w}^{f}$ is the wet weight of the filter, $W_{d}^{c}$ is the dried weight in an oven at $105{ }^{\circ} \mathrm{C} 1.5 \mathrm{~h}$ (filter + granule), $W_{d}^{f}$ is the dry weight of the filter only. With 10 repeated measurements, the f factor was 
determined as 3.48 .

\subsubsection{Fractal aggregate and its permeable property}

A microbial granule is fractal and intra-granule flow was permitted by the highly porous and fractal structure of the granule. Therefore, the drag coefficient was decreased followed by an increase of the settling velocity as compared with the trend predicted by Stokes' law (Li and Ganczarczyk, 1988). The predicted settling velocity, US, can be compared with the actual settling velocity using the ratio (Johnson et al., 1996) given as

$$
\Gamma=\frac{U}{U s}=\frac{\xi}{\xi-\tanh (\xi)}+\frac{3}{2 \xi^{2}}
$$

where the dimensionless permeability factor $\xi$ is a function of the size and the hydraulic permeability of the granule, $\mathrm{k}$, as follows:

$$
\xi=\mathrm{d} / 2 \kappa^{1 / 2}
$$

Based on a comparison between settling velocities observed and predicted from Stokes' law for an impermeable but porous granule, the permeability of a granule can be estimated. The internal permeation of the granule may be more directly indicated by its fluid collection efficiency, $e_{f}$, which is defined as the ratio of the interior flow passing through the granule to the flow approaching it. When Brinkman's extension of Darcy's law is used to describe the interior flow, the fluid collection efficiency of the granule (Chellam and Wiesner, 1993, Li and Logan, 1997) can be calculated by

$$
\mathrm{e}_{f}=\frac{9 U_{s}}{2 \xi^{2} U}
$$

From the above equations, it can be seen that the parameters $\Gamma$ and $e_{f}$ are solely functions of the permeability factor, $\xi$. Both $\Gamma$ and $e_{f}$ increase as the $\xi$ factor decreases. For impermeable particles, as $\xi$ approaches infinity, $\Gamma=1$ and $e_{f}=0$. As the aggregate 
permeability increases, $\xi$ decreases, and $\Gamma$ and $e_{f}$ increase.

\subsection{Specific surface area of granules}

The specific surface area was determined by a Brunauer Emmett Teller (BET) surface area analyzer (Sorptomatic 1990 Surface Area Analyzer, Thermo Fisher Scientific Inc., Waltham, MA, USA). The granule sample was put in the tubes, and the sample were degassed at ambient temperature for $2 \mathrm{~h}$ under $\mathrm{N}_{2}$ flowing.

\subsection{Scanning electron microscope (SEM)}

The surface morphology of granule was characterized using an environmental scanning electron microscope (LEO 1455 VP-SEM, Leo electron microscopy Ltd, UK) without any pretreatment.

\subsection{Analytical methods}

The concentrations of the COD and VSS were measured according to standard methods (APHA, 1998). The measured biogas production was adjusted to a standard temperature $\left(0^{\circ} \mathrm{C}\right)$ and pressure $(760 \mathrm{mmHg})(\mathrm{STP})$. The $\mathrm{CH}_{4}$ gas content was analyzed via gas chromatography (GC, Gow Mac Series 580) equipped with a thermal conductivity detector (TCD) and a $2 \mathrm{~m}$ x $2 \mathrm{~mm}$ stainless steel column packed with a Porapak Q mesh $80 / 100$ with helium as the carrier gas. The temperatures of the injector, detector, and column were maintained at 80,90 , and $50^{\circ} \mathrm{C}$, respectively.

\section{RESULTS AND DISCCUSION}

\subsection{Positive effects of LS-ultrasonication on the AD performance}

In our previous research, two UASBrs (control and ultrasonicator attached UASBrs) 
were operated to assess the positive effects of LS-ultrasonication on the AD performance and the daily $\mathrm{CH}_{4}$ production, as shown in Fig. 1. After the observation of a drastic decrease in the $\mathrm{CH}_{4}$ production coupled with deterioration of the effluent turbidity, likely due to disaggregation of granules and cell rupture (Phase I), granules were re-seeded. The ultrasonication time (UT) and interval (UI) were then changed from $5 \mathrm{~min}$ and 8 hours to 1 sec and 1 min, respectively (Phase II). Compared to the control (un-ultrasonicated UASBr), the COD removal rate was enhanced from $72 \%$ to $85 \%$ after irradiation. The daily $\mathrm{CH}_{4}$ production and specific $\mathrm{CH}_{4}$ production rate were also enhanced by $43 \%$ from 2,254 to 3,219 $\mathrm{mL} /$ day and from 180 to $258 \mathrm{CH}_{4} \mathrm{~mL} / \mathrm{g} \mathrm{COD}$ added, respectively (Cho et al., 2012). In the previous research, explanations of enhanced AD performance after LS-ultrasonication focused on the changes of biological characteristics of methanogenic granules by measuring the dehydrogenase activity and ATP content. However, the changes of physico-chemical characteristics of methanogenic granules after LS-ultrasonication also should be considered, since they are highly related to the transportation of the substrate and nutrients.

\subsection{Physico-chemical properties of methanogenic granules \\ 3.2.1 Size, dry mass, and density}

As shown in Fig. 2, the size of the granules varied from 1.5 to $6 \mathrm{~mm}$ and the dry mass of the granules ranged up to $4 \mathrm{mg}$ for both granules. No significant difference was observed after LS-ultrasonication. However, slightly lower density was observed from the ultrasonicated granules $\left(1.055 \mathrm{~g} / \mathrm{cm}^{3}\right)$ than the control granules $\left(1.075 \mathrm{~g} / \mathrm{cm}^{3}\right)$. Interesting physical features of methanogenic granules (similar size and dry mass but lower density) were observed compared to the control granules, suggesting that the structure of the ultrasonicated granules was expanded or loosened relative to that of the control granules, since density is defined as mass per volume. 


\subsubsection{Fractal dimension}

The fractal dimension is an index for describing the degree of aggregate compactness. In addition, the fractal dimension of an aggregate is related to packing of the particles forming the aggregates and will reflect the aggregate packing factor (Tang and Raper, 2002). Thus, it is considered an important property in floc settling processes. The fractal dimension of an aggregate varies from 1 to 3, with a value of 3 implying a solid spherical structure.

However, in this study, values greater than $3,4.31$, and 3.89 were calculated from the control and ultrasonicated granules, respectively, as shown in Fig. 3. Similar results of fractal dimension exceeding 3 were reported by Dekayir and Rouai (2003). In Voss (1988), this was explained by scaling irregularities and compressibility of the aggregate, and many assumptions were applied for derivation of the model.

On the other hand, this can also be explained by the structure of the granules. According to Lee (1999), the flocs generated in natural systems have a multi-level structure. In addition, the floc formation model of Gorczyca and Ganczarczyk (1999) consists of primary particles, compact flocculi, microflocs, and highly porous flocs, which exhibit different structures and perhaps different fractal dimensions as well. Thus, Lee (1999) stated that the simplest picture for a floc can thereby be viewed as a fractal of fractals (multifractal). Notably, a fractal dimension greater than 3 was reported by Perfect et al. (1993) based on the multifractal fragmentation model. While the proper ranges of fractal dimension remain controversial, lower fractal dimension of the ultrasonicated granules (3.89) than the control granules (4.31) clearly support the aforementioned suggestion, since a lower fractal dimension value implies a looser and more porous aggregate ( $\mathrm{Li}$ and $\mathrm{Yu}, 2011$ ).

\subsubsection{Settling velocity}

Settling velocity is considered to be the single most critical factor for successful operation of a UASBr. Higher settling velocity of the methanogenic granules than the 
conventional sludge flocs commonly results in higher settleability, which is beneficial for the effluent quality and biomass retention. The settling velocities of the control and ultrasonicated granules were varied from 1.46 to $3.26 \mathrm{~cm} / \mathrm{s}$ with an average of $2.44 \pm 0.43$ $\mathrm{cm} / \mathrm{s}$ and from 1.76 to $3.60 \mathrm{~cm} / \mathrm{s}$ with an average of $2.62 \pm 0.51 \mathrm{~cm} / \mathrm{s}$, respectively. Slightly higher settling velocity was observed from the ultrasonicated granules than that of the control granules; this will be discussed with other settling parameters. In addition, settling velocity increased with an increase in granule diameter for both granules, as shown in Figs. 4(a) and 4(b). Values from this study were much larger than that of activated sludge floc (0.17$0.42 \mathrm{~cm} / \mathrm{s}$ ) and hydrogen producing granule (up to $2.32 \mathrm{~cm} / \mathrm{s}$ ) due to their larger size and higher density (Li and Yu, 2011). The dimensionless ratios $(\Gamma)$ between the observed and predicted settling velocities of the control and ultrasonicated granule were in a range of 0.82 2.27 with an average value of $1.30 \pm 0.32$ and $0.88-2.25$ with an average value of $1.32 \pm 0.25$, respectively, as shown in Fig. 4(c). A $\Gamma$ value greater than 1 implies that a certain amount of water was enclosed and remained within the pores of a granule.

\subsubsection{Fluid collection efficiency}

The fluid collection efficiency of the control and ultrasonicated granules were in a range of $0.02-0.48$ with an average value of $0.15 \pm 0.14$ and $0.02-0.47$ with an average value of $0.16 \pm 0.11$, respectively, as shown in Fig. $4(\mathrm{~d})$. They were decreased with an increase in the diameter, possibly due to pore clogging by higher EPS excretion from the larger size of methanogenic granules. The range of fluid collection efficiency of this study was similar with that (0-0.42) in a previous research from anaerobic methanogenic granules (Mu et al., 2006). However, it was higher than the range of hydrogen producing granules $(0-0.19)$, since more excretion of EPS by hydrogen producing granules than that of methanogenic granules appeared to result in a higher possibility of pore clogging ( $\mathrm{Li}$ and $\mathrm{Yu}, 2011$ ).

\subsubsection{Permeability}


Settling behavior of bio-aggregates highly relies on the drag force and permeability through their interior (Tang and Raper, 2002). The characteristic behaviors of the ultrasonicated granules (slightly lower densities and fractal dimensions but slightly higher settling velocities and fluid collection efficiencies) compared to the control granules implied an increase of the methanogenic granules' permeability after LS-ultrasonication. The permeabilities of both granules ranged up to $0.0025 \mathrm{~cm}^{2}$, and average values of the control and ultrasonicated granules were $0.0008 \pm 0.0006 \mathrm{~cm}^{2}$ and $0.0011 \pm 0.0006 \mathrm{~cm}^{2}$, respectively, as shown in Fig. 4(e). 37\% higher permeability of methanogenic granules was observed after LS-ultrasonication. However, the differences between the control and ultrasonicated granules from all settling experiments were less than the standard deviation, and thus those values are not valid in terms of a statistical point of view. However, dealing with various sizes of the methanogenic granules inevitably increased the standard deviation, since methanogenic granules of different size have different settling characteristics. In addition, the difficulties and heterogeneities of the environmental samples also should be considered to evaluate the validity of the results. In spite of the invalidity issues regarding the settling experimental results based on a statistical approach, an increase of methanogenic granules' settling velocities after LS-ultrasonication was definitely observed. This was clear evidence of increased permeability, since an increase of settling velocity could be achieved by a reduction of the drag coefficient after a significant intra-aggregate flow (Li and Yuan, 2002). In short, LS-ultrasonication increased the permeability of methanogenic granules. As a result, penetration of nutrients and the substrate into granules could be enhanced, and more favorable conditions for achieving higher $\mathrm{CH}_{4}$ production appeared to be provided to ultrasonicated granules.

\subsubsection{Scanning electron microscope and specific surface area}

The morphological characteristics of the methanogenic granules are known to be 
substantially influenced by the operating conditions such as sludge property, substrate composition, OLR, feeding strategy, reactor design, and hydrodynamic shear force (Liu et al., 2009). In this study, the significant effects of LS-ultrasonication on the morphology of methanogenic granules were observed for the first time through SEM images (supplementary Fig. S1). Multiple cracks, providing paths for the produced biogas to travel from the core to the surface of the methanogenic granule, were observed; however, much bigger and deeper cracks were observed from the ultrasonicated granules. In addition, many additional craters were observed from the ultrasonicated granules. It appears that the propagated ultrasonic wave generated the numerous craters on the surface of the methanogenic granules; the greater amount of produced biogas resulted in much bigger and deeper cracks than the control granules. As a result of a rougher and more uneven surface, 2.3 times higher specific surface area was observed from the ultrasonicated granules $\left(0.5337 \pm 0.0036 \mathrm{~m}^{2} / \mathrm{g}\right.$ TS $)$ than the control granules $\left(0.1624 \pm 0.0025 \mathrm{~m}^{2} / \mathrm{g}\right.$ TS $)$, which were in a range of previously reported values (0.02-0.074 $\mathrm{m}^{2} / \mathrm{g}$ TS) (Hwu et al., 1996). Higher specific surface area, implying an increase of the contact frequency between the substrate and microorganism, appears to be a more favorable condition for the microbial reactions.

In short, the physico-chemical changes of ultrasonicated granules such as increased permeability and increased specific surface area support that LS-ultrasonication positively affects the methanogenic granules in terms of attaining higher AD performance. As further study, the effects of different ultrasonic conditions of UT and UI on the physico-chemical properties should be investigated along with the $\mathrm{AD}$ performance.

\subsection{Discussion}

Porosity and permeability are closely related parameters. Fluids such as air and water are able to permeate through an aggregate by passing though the pores, and a greater number 
of pores and increased pore size make it easier for fluids to pass through. In general, thus, higher porosity is likely to be accompanied by higher permeability. However, in this study, even though $37 \%$ higher permeability was observed after LS-ultrasonication, no significant change in the porosity of methanogenic granules was observed, maintaining $0.8-0.95$ porosity for both granules (data not shown). Porosity can be defined as the percentage of an aggregate's total volume that is taken up by pores, implying the empty space inside the aggregate, while permeability is the measure of how easily fluid flows through the aggregate or how well pores are connected. Thus, it seemed that LS-ultrasonication only affected the outer part of methanogenic granules, and did not affect the interior of the methanogenic granules. Generated craters on the surface of methanogenic granules appeared to increase the paths for fluids and/or possibly connect pores to each other; the permeability was thereby increased, while no significant changes were obseryed in the porosity.

Increased permeability of the methanogenic granules after LS-ultrasonication could be one of the reasons for enhanced $\mathrm{CH}_{4}$ production due to easier penetration of nutrients and the substrate into granules. However, permeability appears to be more closely related to the production rate than yield. Thus, enhanced $\mathrm{CH}_{4}$ production yield could be explained by the sequential effects of increased permeability. Uptake of soluble $\mathrm{H}_{2}$ by the methanogenic granules was possibly enhanced due to the increased permeability, and it could be accelerated by the increased mixing and agitating effects during ultrasonication (Kwiatkowska et al., 2011). The maintenance of proper $\mathrm{H}_{2}$ pressure then became much easier for the ultrasonicated granules than the control granules, which possibly results in enrichment of syntrophic bacteria and hydrogenotrophic methanogens in a balanced manner. Therefore, it appears that increased permeability positively affected the microbial community structure in terms of enhancing $\mathrm{CH}_{4}$ production. To verify this hypothesis, the microbial community shift after the LS-ultrasonication is analyzed and discussed in part II of this paper. 


\section{CONCLUSIONS}

In this study, the effects of LS-ultrasonication on the physico-chemical properties of methanogenic granules were investigated. Visualized morphological changes indicate that LS-ultrasonication resulted in numerous craters and cracks on the granular surface. As a result, ultrasonicated granules had a 2.3 times higher specific surface area and $37 \%$ higher permeability compared to the control granules, presenting favorable conditions for the transportation of nutrients and the substrate into the granules. The experimental results appear to support that LS-ultrasonication positively affects the methanogenic granules in terms of achieving higher $\mathrm{AD}$ performance.

\section{ACKNOWLEDGEMENTS}

This work (Grants No. 00045331) was supported by Business for Cooperative R\&D between Industry, Academy, and Research Institute funded Korea Small and Medium Business Administration in 2011.

\section{REFERENCES}

1. APHA, AWWA and WEF, 1998. Standard methods for the examination of water and wastewater, 20th ed. Baltimore. American Public Health Association. 2, 57-59.

2. Bougrier, C., Albasi, C., Delgenes, J.P., Carrere, H., 2006. Effect of ultrasonic, thermal and ozone pretreatments on waste activated sludge solubilization and anaerobic biodegradability. Chem. Eng. Prog. 45(8), 711-718.

3. Chellam, S., Wiesner, M.R., 1993. Fluid mechanics and fractal aggregates. Water Res. 27, 1493-1496.

4. Cho,S.K., Kim, D.H., Kim, M.H., Shin, H.S., Oh, S.E., 2012. Enhanced activity of 
methanogenic granules by low-strength ultrasonication. Bioresour. Technol. 120, 84-88.

5. Dekayir, A., Rouai, M., 2003. Basalt pore fractal dimensions from image analysis and mercury porosimetry. Arab. J. Sci. Eng. 28, 223-231.

6. Elbeshbishy, E., Hafez, H., Nakhla, G., 2011. Hydrogen production using sono-biohydrogenator. Int. J. Hydrogen Energ. 36, 1456-1465.

7. Gogate, P.R., Kabadi, A.M., 2009. A review of applications of cavitation in biochemical engineering/biotechnology. Biochem. Eng. J. 44(1), 60-72.

8. Gorczyca, B., Ganczarczyk, L., 1999. Structure and porosity of alum coagulation flocs. Water Qual. Res. J. Can. 34, 653-666.

9. Harrison, S.T.L., 1991. Bacterial cell disruption: a key unit operation in the recovery of intracellular products. Biotechnol. Adv. 9, 217-240.

10. Hwu, C.S., Donlon, B., Lettinga, G., 1996. Comparative toxicity of long-chain fatty acid to anaerobic sludges form various origins. Water Sci. Technol. 34, 351-358.

11. Johnson, C.P., Li, X., Logan, B.E., 1996. Settling velocities of fractal aggregates. Environ.

Sci. Technol. 30, 1911-1918.

12. Kim, D.H., Jeong, E., Oh, S.E., Shin, H.S., 2010. Combined (alkaline + ultrasound)

pretreatment effect on sewage sludge disintegration. Water Res. 4, 3093-3100.

13. Kwiatkowska, B., Bennett, J., Akunna, J., Walker, G.M., Bremner, D.H., 2011.

Stimulation of bioprocesses by ultrasound. Biotechnol. Adv. 29, 768-780.

14. Lee, D.J., 1999. Authors' reply. Water Res. 33, 1116

15. Li, D.H., Ganczarczyk, J., 1988. Flow through activated sludge flocs. Water Res. 22, 789792.

16. Li, W.W., Yu, H.Q., 2011. Physicochemical characteristics of anaerobic $\mathrm{H}_{2}$-producing granular sludge. Bioresour. Technol. 102, 8653-8660.

17. Li, X., Logan, B.E., 1997. Collision frequencies of fractal aggregates with small particles 
by differential sedimentation. Environ. Sci. Technol. 31, 1229-1236.

18. Li, X.Y., Yuan, Y., 2002. Settling velocities and permeabilities of microbial aggregates. Water Res. 36, 3110-3120

19. Liu, X.W., Sheng, G.P., Yu, H.Q., 2009. Physicochemical characteristics of microbial granules. Biotechnol. Adv. 27, 1061-1070.

20. Metcalf, Eddy, 2002. Wastewater engineering: treatment and reuse, New York, McGrawHill.

21. $\mathrm{Mu}$, Y., Yu, H.Q., Wang, G., 2006. Permeabilities of anaerobic $\mathrm{CH}_{4}$-producing granules. Water Res. 40, 1811-1815.

22. Perfect, E., Kay, B.D., Rasiah, V., 1993. Multifractal model for soil aggregate fragmentation. Soil Sci. Soc. Am. J. 57, 896-900.

23. Pilli, S., Bhunia, P., Yan, S., Leblanc, R.J., Tyagi, R.D., Surampalli, R.Y., 2011. Ultrasonic pretreatment of sludge: A review. Ultrason. Sonochem. 18, 1-18.

24. Riesz, P., Kondo, T., 1992. Free radical formation induced by ultrasound and its biological implications. Free Radical Bio. Med. 13, 247-270.

25. Tang, P., Raper, J.A., 2002. Modelling the settling behaviour of fractal aggregate-a review. Powder Technol. 123, 114-125.

26. Voss, R.F. 1988. Fractals in nature: From characterization to stimulation. The Science of Fractal Images. Springer-Verlag, New York, NY, U.S.A.

27. Wang, Q., Kuninobu, M., Kakimoto, K., Ogawa, H.I., and Kato, Y., 1999. Upgrading of anaerobic digestion of waste activated sludge by ultrasonic pretreatment, Bioresour. Technol. $68,309-313$.

28. White, F., 2005. Viscous Fluid Flow, New York, MaGraw-Hill.

29. Zheng, Y.M., Yu, H.Q., Sheng, G.P., 2005. Physical and chemical characteristics of granular activated sludge from a sequencing batch airlift reactor. Process Bioche. 40, 645-650. 
Figure 1 Comparison of AD performance of ultrasonicator attached UASBr with UASB

Figure 2 Dry mass of methanogenic granule

Figure 3 Fractal dimension of the methanogenic granule

Figure 4 Observed and predicted settling velocities of (a) the control granule and (b) ultrasonicated

granule; (c) ratio of the observed and predicted settling velocities of the granule; (d) fluid collection efficiencies of the granule; (e) permeabilities of the granule 
Figure 1 Comparison of AD performance of ultrasonicator attached UASBr with UASB

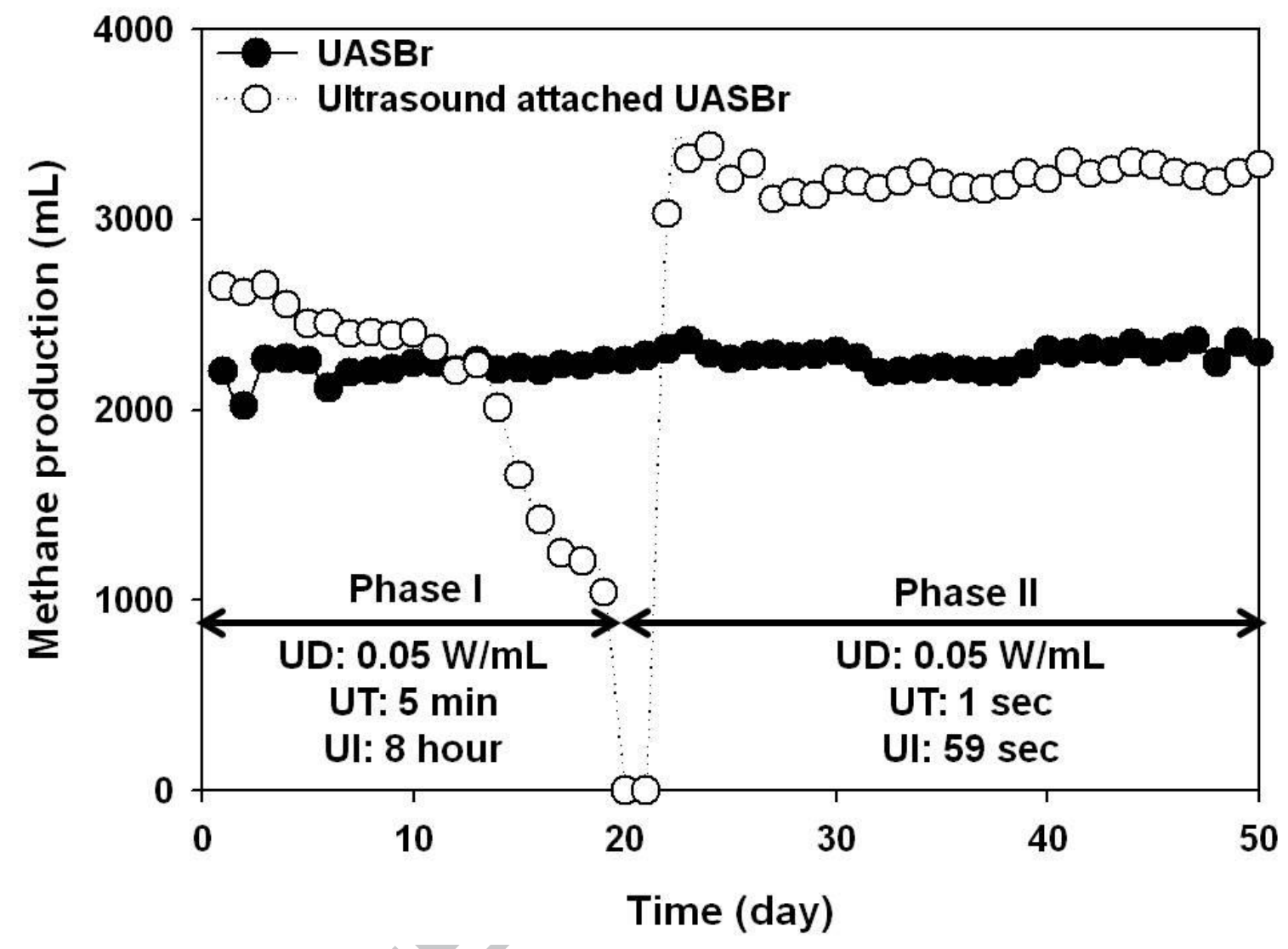


Figure 2 Dry mass of methanogenic granule

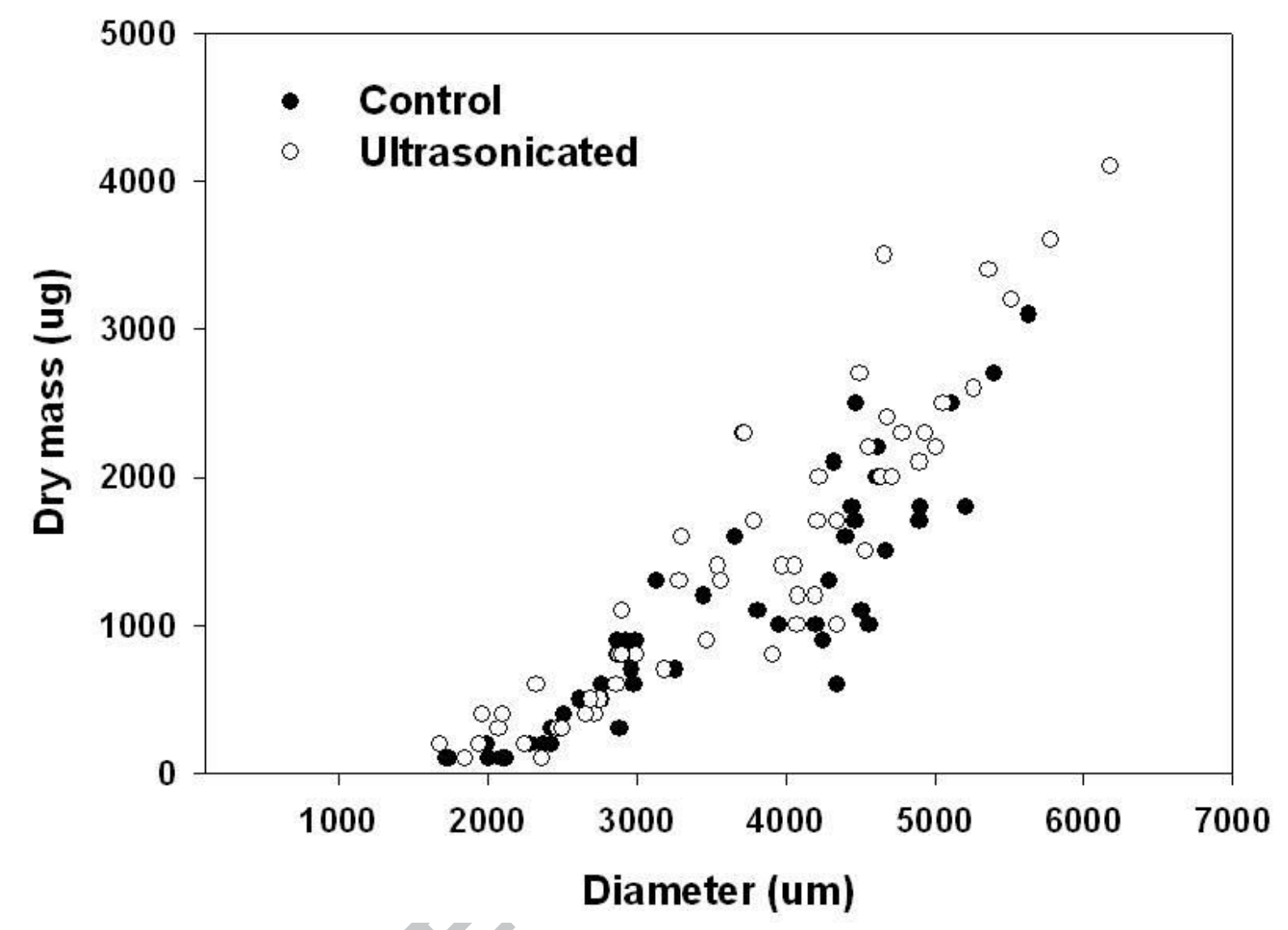


Figure 3 Fractal dimension of the methanogenic granule

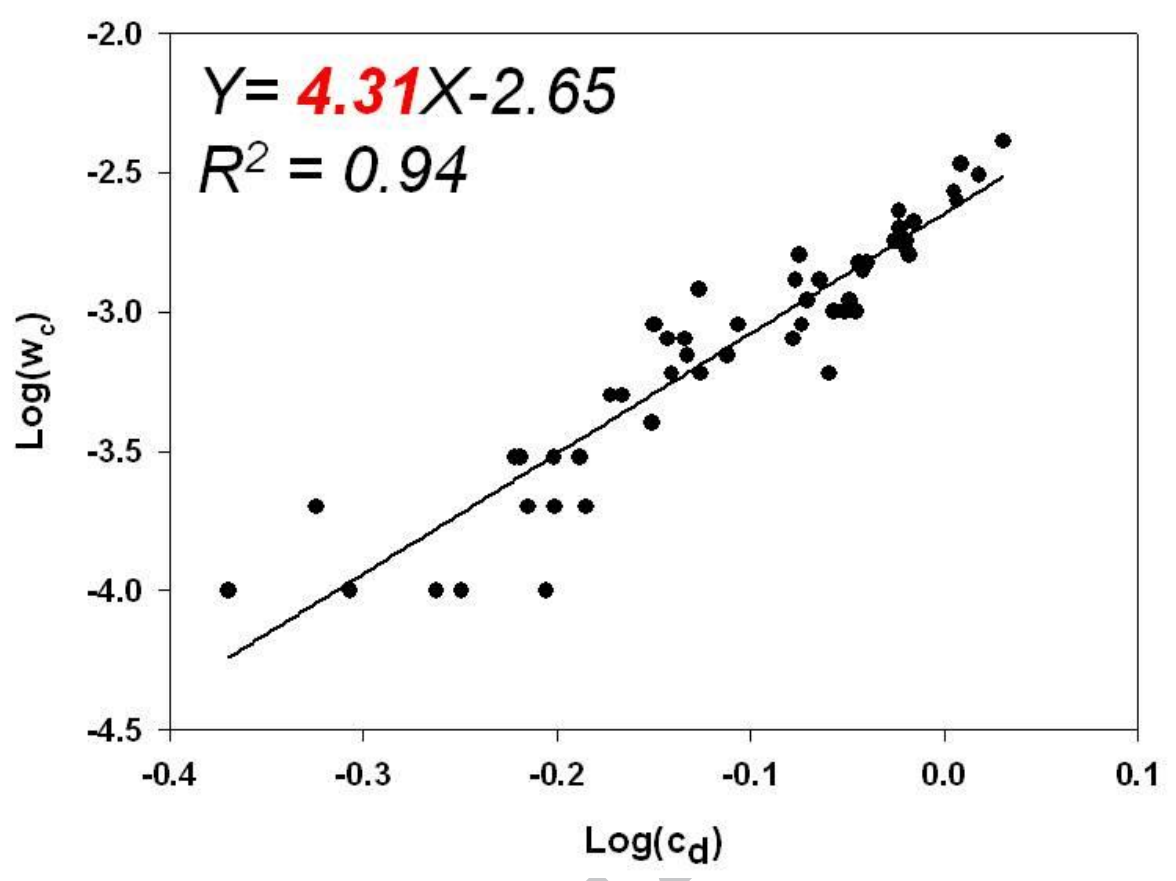

(a) Control

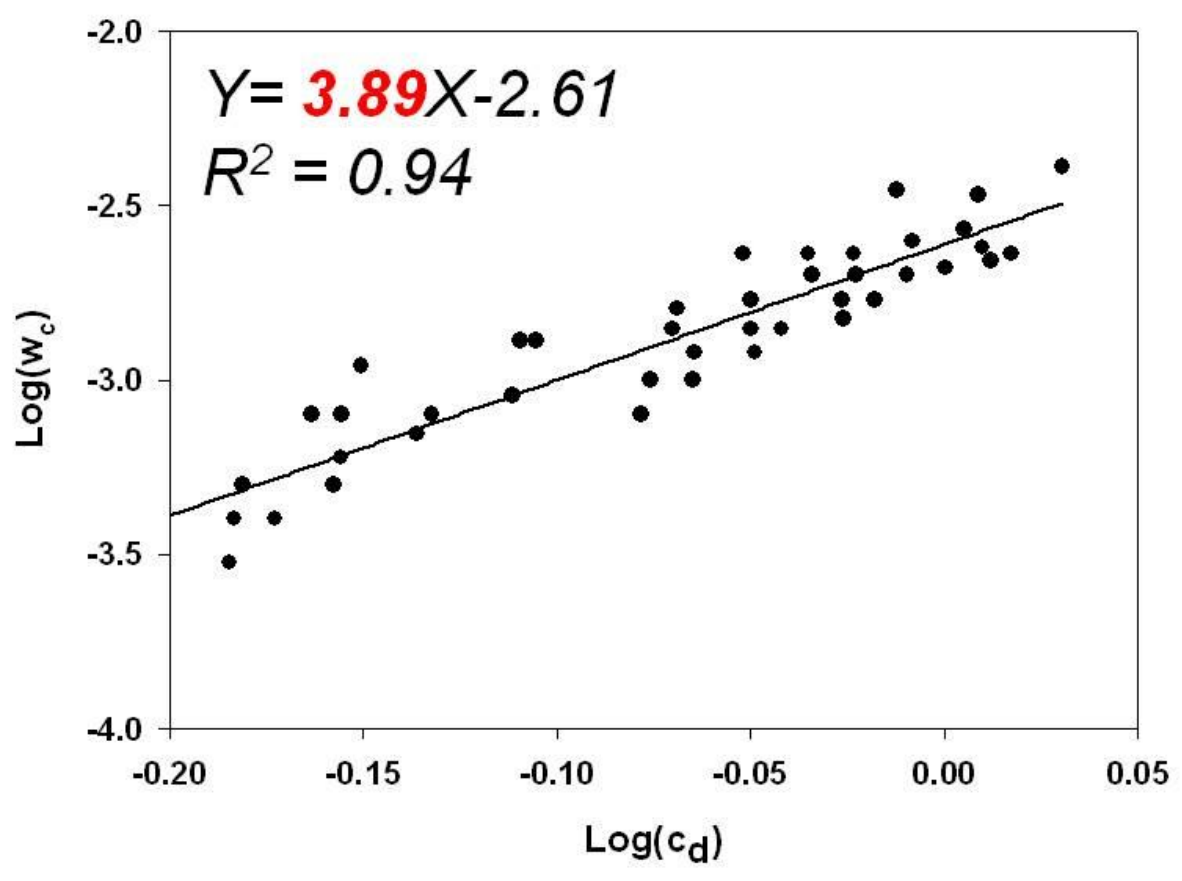

(b) Ultrasonicated 
Figure 4 Observed and predicted settling velocities of (a) the control granule and (b) ultrasonicated granule; (c) ratio of the observed and predicted settling velocities of the granule; (d) fluid collection efficiencies of the granule; (e) permeabilities of the granule

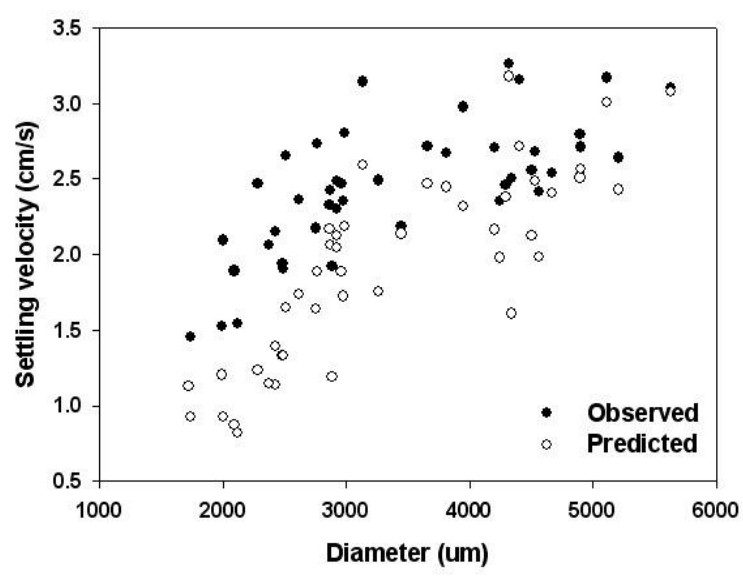

(a)

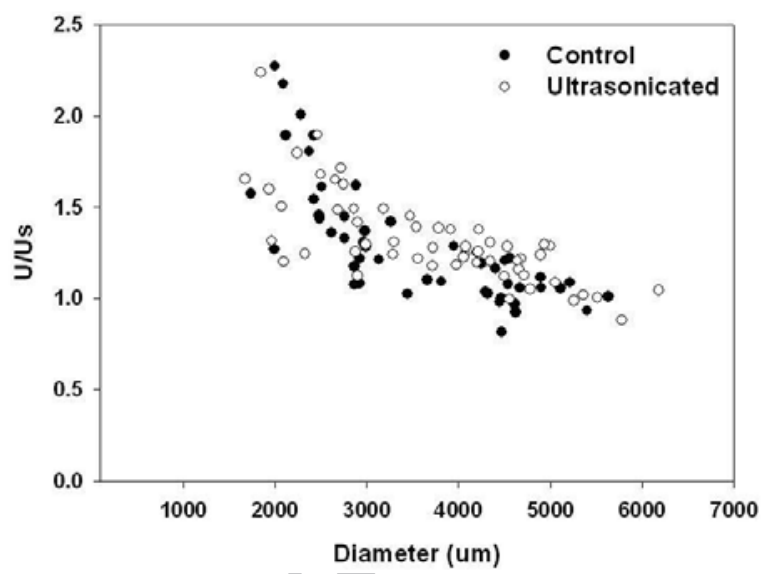

(c)

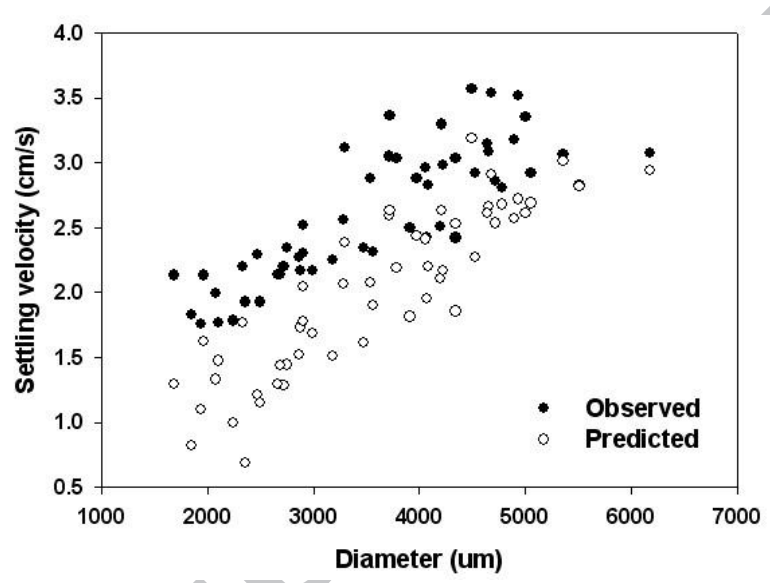

(b)

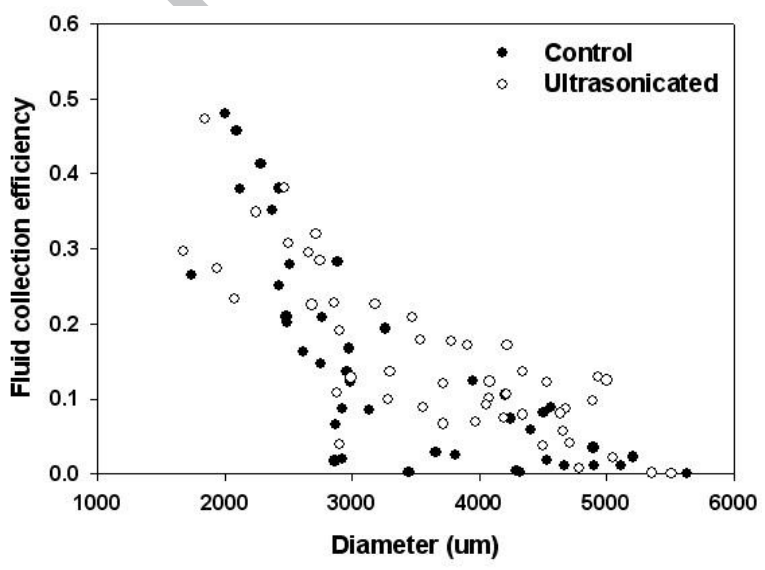

(d)

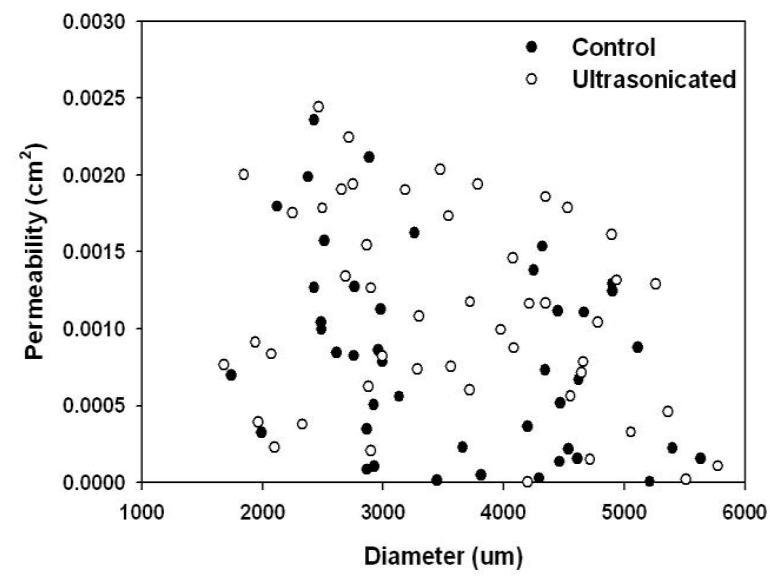

(e) 


\section{Supplementary}

Figure 1 SEM images of the anaerobic granule: (a) control granule, (b) ultrasonicated granule,

(c) magnified control granule (x 150), (d) magnified ultrasonicated granule (x 150),

(e) magnified control granule (x 300), (f) magnified ultrasonicated granule (x 300)

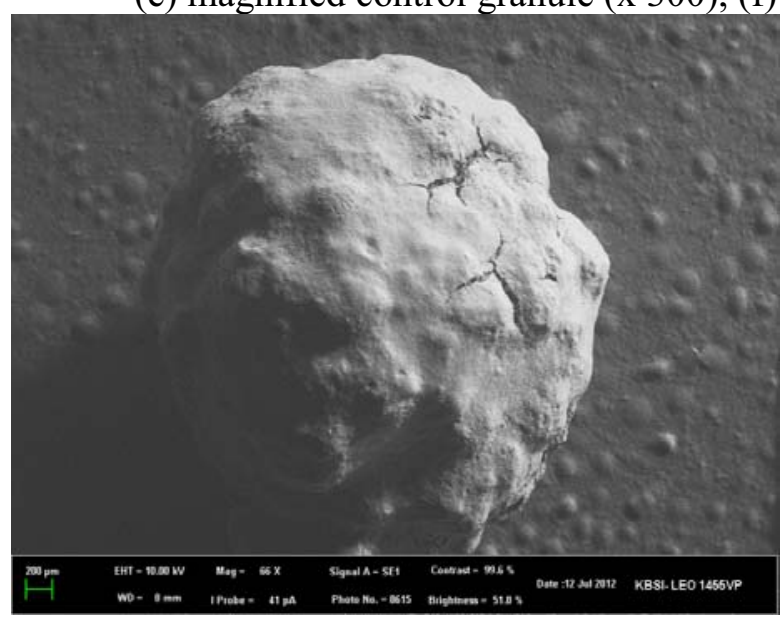

(a)

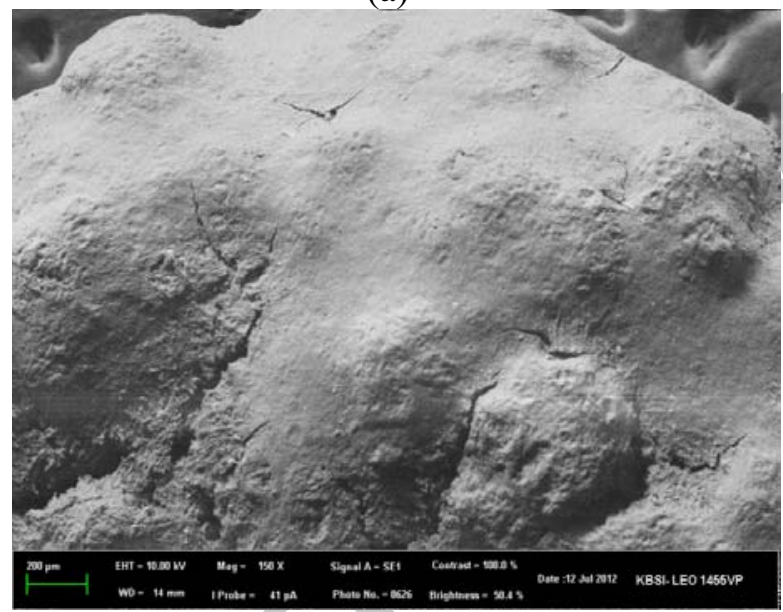

(c)

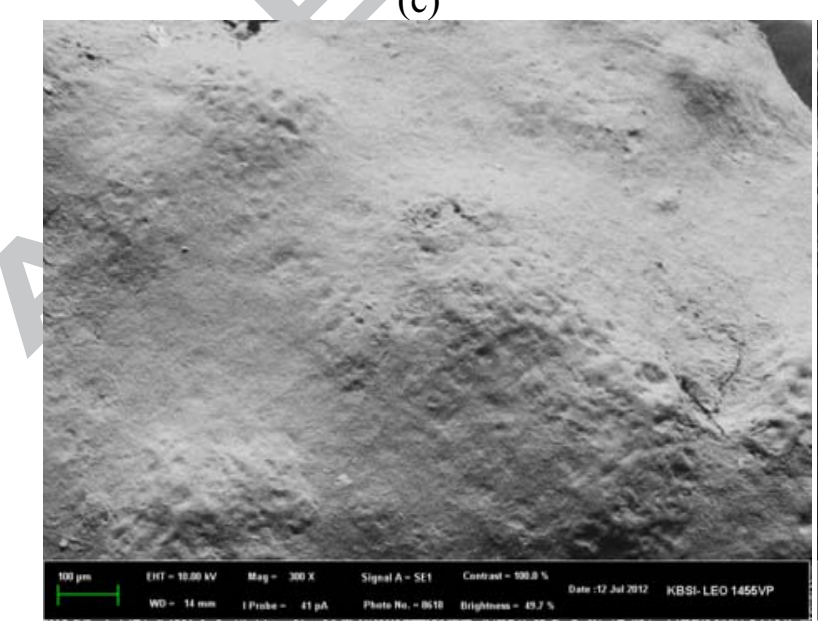

(e)

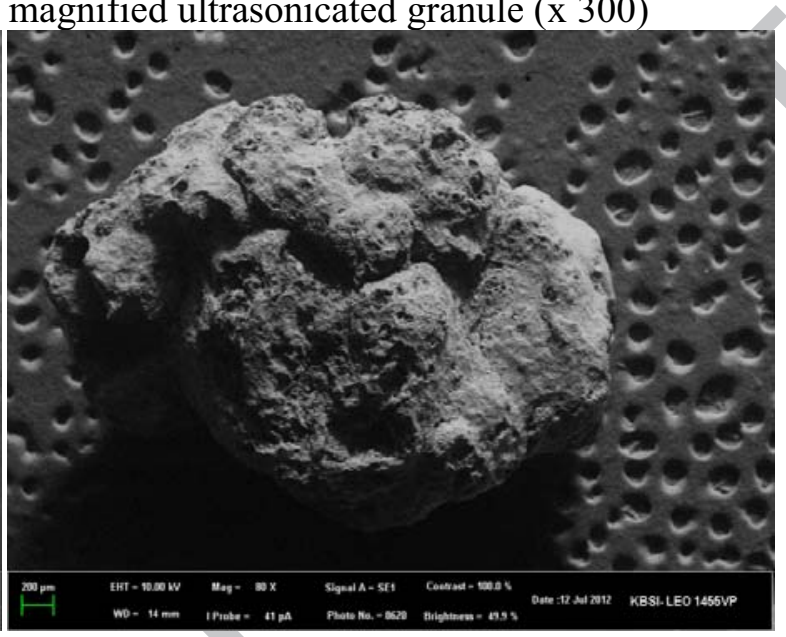

(b)

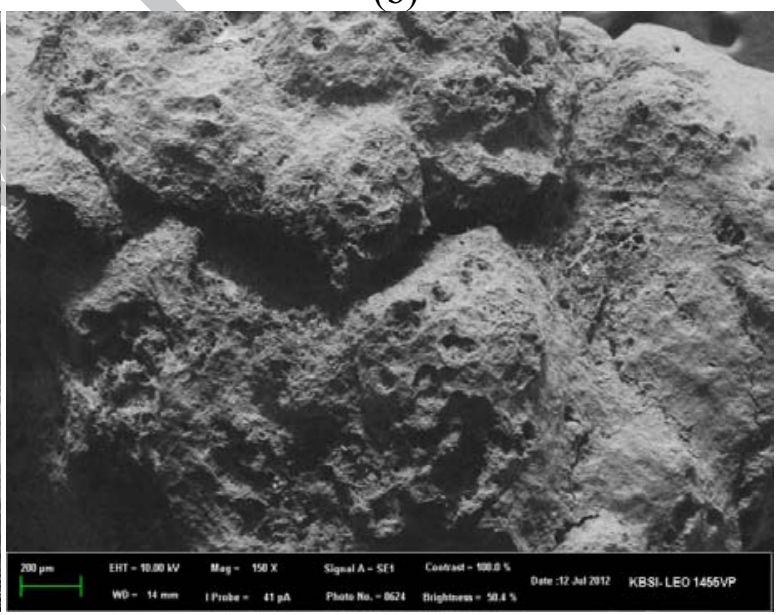

(d)

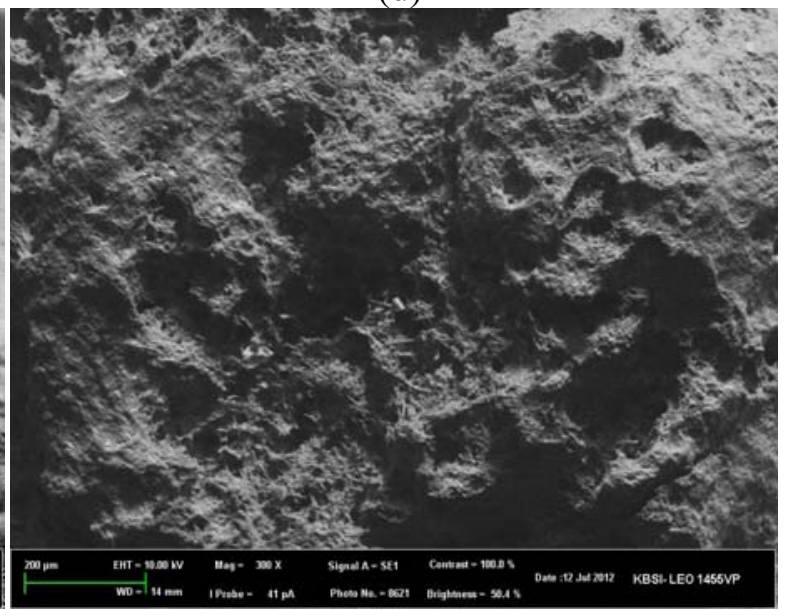

(f) 


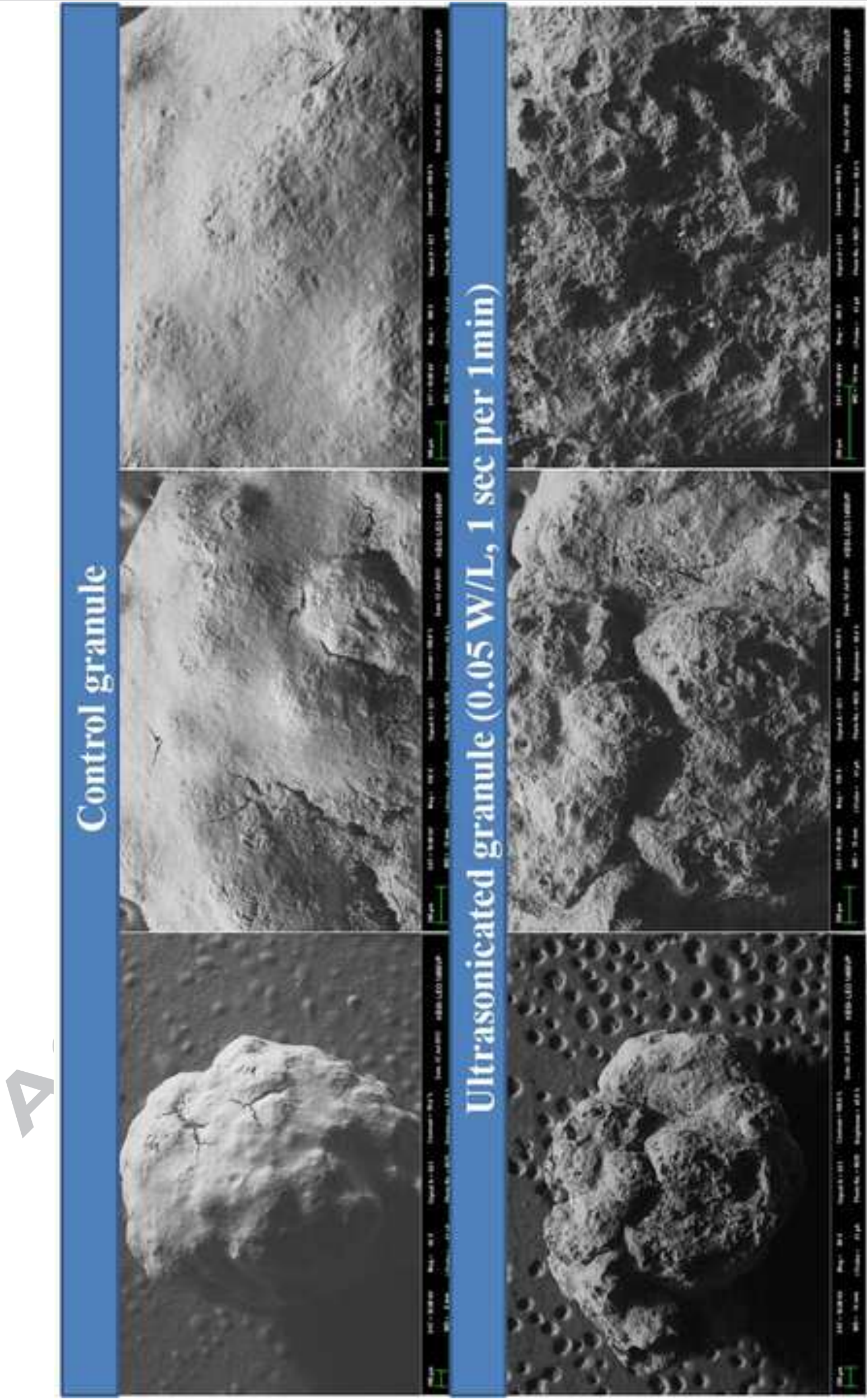




\section{Highlights}

- $43 \%$ higher $\mathrm{CH}_{4}$ production was achieved from UASBr under low strength ultrasound.

- It was explained by the changes of physico-chemical properties of anaerobic granule.

- Ultrasonication resulted in numerous craters and cracks on the granular surface.

- As results, specific surface area was increased by 2.3 times than the control.

- In addition, permeability was enhanced by $37 \%$ compared to the control granules. 